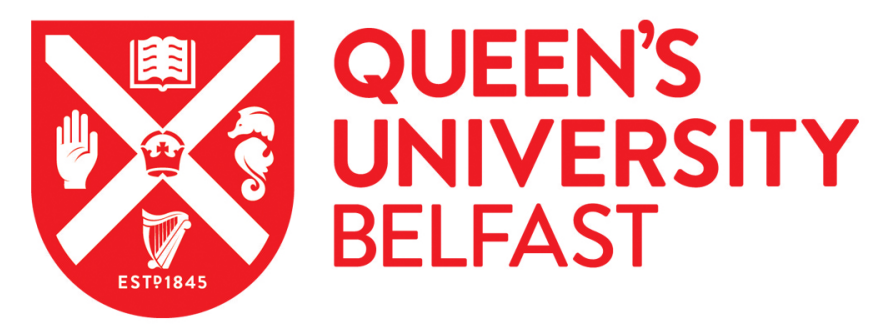

\title{
Child welfare as justice: why are we not effectively addressing inequalities?
}

Davidson, G., Bunting, L., Bywaters, P., Featherstone, B., \& McCartan, C. (2017). Child welfare as justice: why are we not effectively addressing inequalities? British Journal of Social Work, 47(6), 1641-1651.

https://doi.org/10.1093/bjsw/bcx094

\section{Published in:}

British Journal of Social Work

\section{Document Version:}

Peer reviewed version

\section{Queen's University Belfast - Research Portal:}

Link to publication record in Queen's University Belfast Research Portal

\section{Publisher rights}

(c) The Author 2017. Published by Oxford University Press on behalf of The British Association of Social Workers. All rights reserved.

This work is made available online in accordance with the publisher's policies. Please refer to any applicable terms of use of the publisher.

\section{General rights}

Copyright for the publications made accessible via the Queen's University Belfast Research Portal is retained by the author(s) and / or other copyright owners and it is a condition of accessing these publications that users recognise and abide by the legal requirements associated with these rights.

Take down policy

The Research Portal is Queen's institutional repository that provides access to Queen's research output. Every effort has been made to ensure that content in the Research Portal does not infringe any person's rights, or applicable UK laws. If you discover content in the Research Portal that you believe breaches copyright or violates any law, please contact openaccess@qub.ac.uk. 
Article title: Child welfare as justice: why are we not effectively addressing inequalities?

Authors: Gavin Davidson, Lisa Bunting, Paul Bywaters, Brid Featherstone and Claire McCartan

Author Affiliations: Gavin Davidson is a Senior Lecturer in Social Work at Queen's University Belfast, Lisa Bunting is a Lecturer in Social Work at Queen's University Belfast, Paul Bywaters is a Professor of Social Work at Coventry University, Brid Featherstone is a Professor of Social Work at the University of Huddersfield and Claire McCartan is a Research Assistant at Queen's University Belfast

Corresponding author's contact details: Gavin Davidson, Senior Lecturer in Social Work, School of Social Sciences, Education and Social Work, Queen's University Belfast, Northern Ireland, BT7 1NN. Email: g.davidson@qub.ac.uk

Funding: The Child Welfare Inequalities Project was funded by the Nuffield Foundation Accepted for publication by the British Journal of Social Work on 05.07.17 


\section{Child welfare as justice: why are we not effectively addressing inequalities?}

Keywords: Child; family; policy; inequality; justice

Abstract: This theoretical paper addresses fundamental questions raised by a four nation comparison of child welfare interventions in the UK, the Child Welfare Inequalities Project, which has highlighted differences between and within countries. The Project analysed administrative data to examine the relationship between deprivation and state intervention. This Project builds on research by Coventry University which established both a social gradient in child welfare interventions and an inverse intervention effect similar to the inverse health law (better health care in more affluent areas). These empirical findings raise, but do not fully answer, whether such inequalities in child welfare interventions should be addressed. In order to consider this complex question this article aims to explore theoretical ideas from other disciplines to provide important perspectives on such inequalities. These perspectives include ideas from political theory, psychology and moral philosophy. They suggest that child welfare should be: structured in a fairer way (based on Rawls' work on justice); that people think society is more equitable than it is and would prefer it to be more equally distributed (based on Norton and Ariely's work on attitudes to inequality); and that it is ethically irrational not to address this (based on Singer's work on moral distance).

\section{Introduction}

It is long-established and well-accepted that there is a social gradient in health (Black, 1980; Acheson, 1998; Marmot, 2010). In other words the more deprived your circumstances, the more likely it is that you will experience health problems and ultimately die at a younger age. There is also growing evidence of a similar gradient in child welfare. So the more deprived your circumstances the more likely it is that you will experience child welfare interventions which, although may be influenced by a range of factors, are the nearest proxy we have for abuse and neglect (Authors' own, 2015a, 2015b, 2016a, 2016b, 2017). Despite this clear evidence that poverty is a contributory causal 
factor in children's health and welfare - arguably the most important single factor - social work policy and practice have not effectively addressed this issue at any level. This is not to suggest that poverty is the only factor in the abuse, neglect and health problems that children experience, or that it is even necessary or sufficient, but that the graduated impact deprivation has on the likelihood of these difficulties should make it of more central importance to child and family social work in the $21^{\text {st }}$ century. Theoretical perspectives from other disciplines may facilitate fresh thinking about this issue so this article aims to explore, from different perspectives, both why inequalities, or more accurately inequities (avoidable inequalities), should be addressed and why this has not yet become the main priority of social work policy and practice.

This article has been developed as part of a four nation comparison of child welfare intervention rates in the UK which has highlighted differences between and within countries. Using administrative data to examine the relationship between deprivation and state intervention, this Project builds on research by Coventry University which established both a social gradient in welfare interventions and an inverse intervention effect, similar to the inverse health law (Hart, 1971) of better health care in more affluent areas and of more context specific inequalities along the gradient (Authors' own, 2014; 2016a, 2017). This project therefore raises questions about: why there are context-related differences in welfare and interventions; whether more intervention is necessarily better; and why these issues are important.

As part of the Project, some of the underlying theoretical ideas about why inequalities in child welfare and child welfare interventions may be problematic have therefore been explored. These include ideas from political theory (Rawls, 1971), psychology (Norton and Ariely, 2011) and moral philosophy (Singer, 1997). Rawls (1971), a political philosopher, argues that if we were to develop the structures of society from behind a veil of ignorance, unbiased by knowledge of what our own circumstances were to be, then we would create a much fairer system. Norton and Ariely (2011) 
add empirical research to these political arguments which found that a representative sample of people in the US thought society to be more equitable than it is and would prefer it to be even more so. The third set of ideas, this time from moral philosophy, come from Singer (1997) who gives an example of the drowning child, a scenario in which we personally encounter a child in immediate danger. He suggests that it is ethically irrational that we do not respond in the same way when children are at risk of harm but not geographically, or indeed temporally, in front of us. This theoretical example was given additional poignancy and weight by the public response to the tragic and real example of Alan Kurdi, the Syrian boy who drowned and whose body was photographed on a beach in Turkey. Together these arguments and research studies suggest that in general people want a more equitable society, especially if they are more aware of the realities of deprivation.

\section{Inequalities in child welfare and child welfare interventions}

The empirical research which has provoked this theoretical discussion has been completed as part of the Child Welfare Inequalities Project, a mixed methods comparative study across the four UK countries, which aimed to map and understand inequalities in child welfare intervention rates. The definition of child welfare interventions used by the Project included: all children formally identified as 'Children in Need'; all children subject to child protection planning or registration; and all 'Looked after Children'. In the absence of available data on rates of child abuse and neglect, the intervention rates, whilst an imperfect indicator, also provide the nearest proxy we have on abuse and neglect. It is also widely acknowledged that, although intervention rates are not a direct indicator of abuse and neglect, it is widely acknowledged that the extent of maltreatment is hugely under-reported and the official rates are likely to be an under-estimate (Munro 2012; Stoltenborgh 2015). For the purpose of the Project, inequalities in child welfare interventions were defined as when children and/or their parents face unequal chances, experiences or outcomes of involvement with child welfare services that are systematically associated with structural social disadvantage and are unjust and avoidable. 
The Project built on the findings of an earlier study conducted in the West Midlands in England (Authors' own, 2014, 2015a). It examined the relationship between being on a child protection plan or being looked after with area level measures of deprivation as the indicator of structural social disadvantage. The West Midlands study included 13 Local Authorities which represented $10.5 \%$ of all children in England, $10.6 \%$ of children on a child protection plan (4546) and $11.3 \%$ of all looked after children (7210). Using postcode data, it was then possible to examine child welfare interventions at the lower super output area, which are defined geographical areas with an average of about 1500 residents, to explore possible associations with area level deprivation. It found that the rate of children on child protection plans in the most deprived areas (70.1 per 10,000 children) was approximately 10 times higher than those in the most affluent areas $(7.0$ per 10,000$)$ with a reasonably consistent gradient in between. The pattern held for looked after children with the rate in the most deprived areas being 108 per 10,000 compared to 9.2 per 10,000 in the most affluent areas. So, overall a child's chances of being subject to a formal child welfare intervention is much greater at higher levels of deprivation.

It is not possible from these findings alone to establish why these differences exist and or whether they are necessarily problematic for social work. The most benign, if unlikely, interpretation is that the increase in child welfare interventions along the social gradient is an appropriate and proportionate response to increasing need. Even if that were the case, that explanation does not address the underlying question of whether and how such differences in child welfare and associated life chances should be more of a priority. Other possible interpretations include that there is an over-identification of child welfare concerns in deprived areas and/or an underrepresentation in more affluent areas. Those more service-focused explanations also seem unlikely to fully explain the extremely consistent gradient across such a wide geographical area and high number of children. 
The initial study also enabled, for the first time, relatively small neighbourhoods to be compared. This uncovered inequalities between areas of similar levels of deprivation depending on whether they were in the context of an affluent or deprived Local Authority area. The measure used to provide an indicator of deprivation for small neighbourhoods and Local Authorities was the Index of Multiple Deprivation (IMD) score (Department of Communities and Local Government, 2011). This analysis found that for any given level of neighbourhood deprivation, a child in an affluent local authority is more likely to be subject to a child welfare intervention than a child in a neighbourhood of similar deprivation but in a deprived local authority (Authors' own, 2014). Again, the reasons for these inequalities may be complex but this more nuanced finding undermined the possibility that the gradient in interventions could simply be a reflection of a gradient in need. The findings have been reinforced by the four nations Project which has not only established that the same relationship between deprivation and child welfare intervention rates exists across the UK but has also established further inequalities between countries (Authors' own, in press).

These findings establish that there are inequalities in both child welfare and child welfare interventions, and this raises the question of whether such inequalities, whether they are associated with wider inequalities in society and/or inequalities in the provision of social work interventions, are problematic and, if so, why and for whom? In order to explore these issues further the Project has drawn on theoretical perspectives from different disciplines that focus more on the fairness, desirability and ethics of inequalities.

\section{Political philosophy perspectives on child welfare}

The political philosophy of John Rawls, especially in his seminal book first published in 1971 (revised 1999), 'A Theory of Justice' may help address the question of whether society, and so child welfare, should be structured in a more equitable way? Rawls argued that in constitutional democracies, 
which are founded on social co-operation, justice should be the central organising principle and promoted regardless of the wider political context of the society. In order to determine what principles of justice that would be fair to all, regardless whether they were motivated more by selfinterest or concern for others, he developed a thought experiment - that the principles should be determined from behind 'a veil of ignorance' where we would have no knowledge of the characteristics of our lives. He argued that in those circumstances society would be structured in a way that was fairer for all regardless of the relative advantage or disadvantage of the circumstances of birth. He proposed that society should therefore be based on "the principles that free and rational persons concerned to further their own interests would accept in an initial position of equality as defining the fundamental terms of their association. These principles are to regulate all further agreements; they specify the kinds of social co-operation that can be entered into and the forms of government that can be established. This way of regarding the principles of justice I shall call justice as fairness." (Rawls, 1999, p. 10)

Wakefield (1988a and b, 1999) has applied these ideas to social work and argued that the organising value of social work is distributive justice so the central aim of social work is to ensure that everyone has the fair, social minimum of economic and social goods. He clarifies that Rawls' 'veil of ignorance' is a means by which we can attempt to agree these organising principles for society and social work which are not influenced by our own immediate priorities, desires and preferences. This is not necessarily arguing for a society that is entirely equal but one in which there is a robust safety net for all and economic and social goods, including social services, that are distributed and provided in a fair and unbiased way.

Whitt-Woosley and Sprang (2014) have, more specifically applied Rawls' Theory of Justice to child welfare asking: 
"What would child welfare policy look like if created without any knowledge of whether you would be entering into the inherent contract as a maltreated child, a maltreating parent, a foster parent, a judge, a child protection worker, or any other member of society who stands to benefit or suffer the costs of individuals being harmed and treated unjustly? It seems logical that if one could truly undertake the thick veil of ignorance described by Rawls and suspend the false notion that child maltreatment only concerns an undesirable segment of society, then we would all favor heavier investment in primary and secondary prevention services to eliminate many of these justice dilemmas from occurring and create greater equality of opportunity regarding the resources necessary to sustain healthy families." (p.127)

This interesting and illuminating perspective from political philosophy therefore suggests that, in a democratic society based on some level of social cooperation, avoidable inequalities in child welfare and child welfare interventions that are influenced by where you live in that society, regardless of whether they advantage or disadvantage you, are problematic because they are unjust. WhittWoosley and Sprang (2014) suggest that including all of the relevant perspectives in the development and provision of services could lead to a greater emphasis on prevention, family support, social capital access to health care, structural factors as well as access to specialised child welfare services.

\section{Psychological perspectives on inequalities in child welfare}

It is perfectly reasonable to suggest that Rawls' veil of ignorance, whilst perhaps a beautiful concept, is unachievable as we cannot suspend knowledge of ourselves and societies, so we should explore further what people, in full knowledge of their circumstances, think of how resources should be distributed in society. Norton and Ariely (2011) have done so in the United States by asking a nationally representative online panel $(n=5522)$ their views on how wealth is and should be 
distributed. Initially they devised a task based on Rawls' work. They presented people with three unlabelled pie charts representing three possible distributions between the five segments of the society pie: a perfectly even split between societal quintiles; percentages which represented Sweden's distribution; and one which represented the distribution in the US. Participants were then asked to consider which society they would prefer with the Rawlsian premise "In considering this question, imagine that if you joined this nation, you would be randomly assigned to a place in the distribution, so you could end up anywhere in this distribution, from the very richest to the very poorest" (p. 10). They found that $92 \%$ of the representative American panel preferred the Swedish distribution.

Again it could be argued this was because of the 'veil of ignorance' premise but they also then asked people to estimate the current distribution of wealth in the United States and what they felt it should be. They found that people estimated the percentage of wealth owned by the most affluent $20 \%$ to be $59 \%$ whereas it is in fact $84 \%$. They also asked participants what they felt it should be and the estimate was $32 \%$. So, not only did people dramatically underestimate the current level of inequalities they also expressed a preference for an even more equitable distribution than their under-estimate. A fascinating aspect of that study was that there was a high level of consensus between different societal groups including across gender, political orientation and income. So they found even relatively affluent people who were politically right of centre also underestimated the level of inequality and felt society should be even more equal than their underestimate.

Although perspectives on wealth inequalities are not necessarily directly transferable to views on child welfare and associated interventions, these findings do suggest that people's general preferences, even when they are fully informed of their own circumstances and regardless of political affiliations, are for more equitable societies than we currently have. 


\section{Moral perspectives on inequalities in child welfare}

The final perspective to be considered to inform the debate about child welfare inequalities is from moral philosophy. Peter Singer (1997) developed another thought experiment to explore whether it is morally right and or logical for us to prioritise those who we are aware of and or are geographically closer to. He sets the premise that we are out walking and see a child who has fallen into a shallow pond and is in danger of drowning. Singer suggests that most people would probably not hesitate to wade in and rescue the child. Even if this involved some cost to ourselves, at the very least, time and some discomfort, possibly missing what we were on our way to, maybe even costing us some new clothes and shoes. Singer then puts the question "would it make any difference if the child were far away, in another country perhaps, but similarly in danger of death, and equally within your means to save, at no great cost - and absolutely no danger - to yourself?" He acknowledges that we do tend to prioritise those who are closer to us, and family and friends are important, but he suggests that, once we have achieved the necessities of life, not to redistribute excess wealth to those in immediate need, regardless of where they are, is irrational (Vanags, 2017). Recently Kearns et al. (2014) have added a further empirical dimension to these ideas of moral distance as they found that, in the UK, attitudes to redistribution are influenced by your proximity to deprivation.

Singer also argues that there may be a harmony between a more morally responsible, equitable society and self-interest. He suggests that inequalities make us unhappy and ethical actions give us meaning, purpose and indirectly happiness more effectively than the direct pursuit of pleasure without regard for others. Wilkinson and Pickett's (2009) quantitative analysis of the association between more equal societies and better outcomes provides evidence for this.

\section{Why are we not effectively addressing inequalities?}


If we more or less agree that society should be fairer, that most people want it to be more equitable and that our individual response to a drowning child should inform our societal response to abuse and neglect, then why are the relevant policies, services and outcomes not better? These ideas from political philosophy, psychology and moral philosophy also provide some possible explanations for why addressing inequalities is not currently prioritised in child welfare policy, services and practice.

The first is that current policy discourses do not approach the issues from an unbiased perspective to design child welfare services that are fair for all. In other words the starting point for policy on child welfare and the associated services is not from behind a 'veil of ignorance' concerned with issues of justice. The debate is instead influenced by how child welfare services have developed over time, often in response to high profile and tragic cases, into an individualised child protection system focused on risk of harm (Parton, 2014). The way the narrative is framed is therefore very important. So, for example, when people vote, they do not have the Rawlsian opportunity to express a specific preference for the principles of justice which would determine child welfare or indeed to vote for more resources specifically for child welfare services. Instead the current political debates focus on issues, such as Brexit and immigration, which may lead to people, even those experiencing the negative impact of child welfare inequalities, to vote for parties which will further reinforce such inequalities. There are therefore explanations around a democratic deficit in policy related to child welfare and a wider issue about the current structure and focus of political debate.

Related to the relative under prioritising of child welfare inequalities in political and societal discourse, it may also be that there is a knowledge gap between what people think is happening in child welfare and the actual extent of the inequalities and inadequacies of current responses. Norton and Ariely's (2011) findings would suggest this and they offer a number of possible explanations. They argue that in addition to underestimating inequality, people may also overestimate their own opportunities for social mobility. They also propose that, although they found a high level of 
consensus across political affiliations, this consensus may be lost in the traditional party political debates. Finally, in an explanation which links to Singer's ideas of moral distance they suggest that there is a disconnect between attitudes to inequality and policy preferences. In other words people may state and hold a preference for greater equality but disagree with policies that would achieve it.

Singer's work is also relevant to the nature of democracy and suggests that a political distance has been created between societal decisions about the distribution of resources and social work decisions about individual families and children - so people may not have the opportunity to vote for what their preferences are for child welfare policies and services. This democratic deficit may be reinforced as people who are affected most by child welfare interventions may be underrepresented in the wider political system. Singer's perspective also provides some explanation for why there appears to be relatively little concern about everyday anonymous inequities but widespread outrage at individual cases where there is a name and an image.

\section{Conclusion}

These perspectives from other disciplines suggest our current approach to child welfare, which does not effectively address inequities, is politically unjust (Rawls), not what most people want (Norton and Ariely) and morally irrational (Singer). Based on these arguments from across disciplines, if we agree that society should be fairer and, as part of that, child welfare interventions should be more equitable, then it raises the question of why social work policy, services and outcomes do not reflect this? Three interacting explanations have been suggested, again drawing on these ideas from political theory, moral philosophy and psychology. The first is that current policy discourses do not approach the issues from an unbiased perspective to design child welfare services that are fair for all but rather focus on identifying specific 'Troubled families' and individual protection issues. The second suggests that people may be unaware of the extent and impact of inequalities and there may also be an associated disconnect between people's abstract preferences and their views on specific 
policies. The third set of overlapping explanations relates to the nature of democracy and suggests that a political distance has been created between societal decisions about the distribution of resources and social work decisions about individual families and children. Recent policy consensus on the importance of early intervention, although not without controversy (Authors' own, 2014), does suggest there are opportunities to better argue and communicate how inequities can and should be addressed. Intervening to support and protect child welfare is a central aspect of social work and a crucial aspect of society. This article does not challenge the need for intervention but it does suggest that avoidable inequalities in child welfare and child welfare interventions are concerning. Drawing on these wider theoretical and empirical perspectives helps establish why inequalities should be of more central importance to child and family social work. They also inform the perhaps more complex question of how this can be most effectively achieved. 


\section{References}

Acheson, D. (1998) Independent Inquiry into Inequalities in Health Report, London, Department of Health.

Black, D.A.K. (1980) Inequalities in Health, London, Department of Health and Social Security. Bywaters, P., Brady, G., Sparks, T. and Boas, E. (2016a) 'Child welfare inequalities: new evidence, further questions, Child and Family Social Work, 21, 369-380.

Bywaters, P., Bunting, L., Davidson, G., Hanratty, J., Mason, W., McCartan, C. and Steils, N. (2016b) The relationship between poverty, child abuse and neglect: an evidence review, York, Joseph Rowntree Foundation. Available at https://www.jrf.org.uk/report/relationship-between-povertychild-abuse-and-neglect-evidence-review

Bywaters, P. (2015a) 'Inequalities in child welfare: towards a new policy, research and action agenda', British Journal of Social Work, 45(1), 6-23.

Bywaters, P., Brady, G., Sparks, T., Bos, E., Bunting, L., Daniel, B., Featherstone, B., Morris, K. and Scourfield, J. (2015b) 'Exploring inequities in child welfare and child protection services: explaining the "inverse intervention law", Children and Youth Services Review, 57, October, 98-105.

Bywaters, P., Brady, G., Sparks, T., \& Bos, E. (2014) ‘Child welfare inequalities: New evidence, further questions', Child and Family Social Work, Online advance access, DOI: 10.1111/cfs.12154.

Department of Communities and Local Government (2011) The English Indices of Deprivation, www.gov.uk/government/uploads/system/uploads/attachment data/file/6871/1871208.pdf 
Kearns, A., Bailey, N., Gannon, M., Livingston, M., \& Leyland, A. (2014) '“All in it together”? Social cohesion in a divided society: attitudes to income inequality and redistribution in a residential context', Journal of Social Policy, 43(3), 453-77.

Marmot, M. G., Allen, J., Goldblatt, P., Boyce, T., McNeish, D., Grady, M., and Geddes, I. (2010). Fair society, healthy lives: Strategic review of health inequalities in England post-2010, London, Marmot Review. Available at www.ucl.ac.uk/marmotreview.

Munro, E., \& Manful, E. (2012). Safeguarding children: a comparison of England's data with that of Australia, Norway and the United States. London: Department for Education.

Norton, M. I. and Ariely, D. (2011) 'Building a better America - One wealth quintile at a time', Perspectives on Psychological Science, 6(1), 9-12.

Parton, N. (2014) Social Work, Child Protection and Politics: Some Critical and Constructive Reflections. British Journal of Social Work, 44 (7), 2042-2056.

Rawls, J. $(1971,1999)$ A Theory of Justice, Revised Edition, Boston, Harvard University Press.

Singer, P. (1997) 'The drowning child and the expanding circle', New Internationalist, 289, 28-30.

Stoltenborgh, M., Bakermans-Kranenburg, M. J., Alink, L. R., \& IJzendoorn, M. H. (2015). The Prevalence of Child Maltreatment across the Globe: Review of a Series of Meta-Analyses. Child Abuse Review, 24(1), 37-50. 
Vanags, P. (2017) 'Applying Singer's work to child welfare' - personal correspondence. $18^{\text {th }}$ April 2017.

Wakefield, J.C. (1988) 'Psychotherapy, distributive justice, and social work: Part 1: Distributive justice as a conceptual framework for social work', Social Service Review, 62(2), 187-210.

Wakefield, J. C. (1988b) ‘Psychotherapy, distributive justice, and social work: Part 2: Psychotherapy and the pursuit of justice', Social Service Review, 353-382.

Wakefield, J. C. (1998) 'Psychotherapy, distributive justice, and social work revisited', Smith College Studies in Social Work, 69(1), 25-57.

Whitt-Woosley, A. and Sprang, G. (2014) 'When Rights Collide: A Critique of the Adoption and Safe Families Act from a Justice Perspective', Child Welfare, 93(3), 111-134.

Wilkinson, R. and Pickett, K. (2009) The Spirit Level: Why more equal societies almost always do better, London, Allen Lane. 